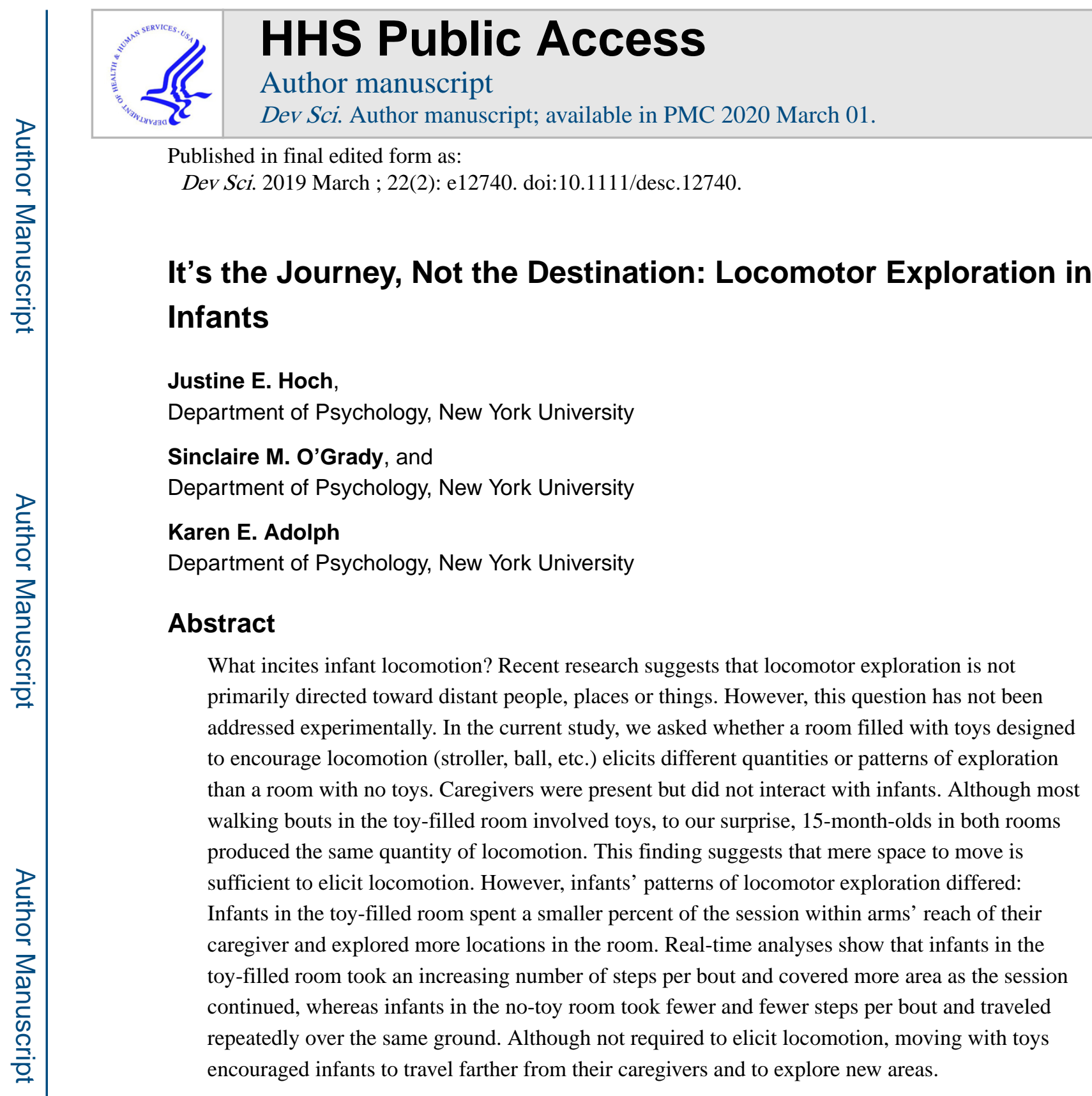

\title{
Keywords
}

infant locomotion; exploration; peragration; walking; gross motor play

\begin{abstract}
Infants walk a lot. During free play with a caregiver, the average toddler takes about 2400 steps and travels the length of 7.7 American football fields per hour (Adolph et al., 2012). But why? Certainly, massive amounts of locomotor experience serve long-term functions: Experience with locomotion teaches infants about their growing bodies and developing skills, and allows them to explore the larger physical and social world. But infants do not set out to gain locomotor experience and the benefits it entails. Instead, accumulated locomotor experience is the byproduct of many real-time bouts of locomotion, each with its own short-
\end{abstract}

Corresponding author: Karen Adolph, 4 Washington Place, Room 415, New York, New York, 10003. karen.adolph@nyu.edu. Telephone: 212-998-9058. 
term motivation. So, what motivates infants to move? The most widely held commonsense hypothesis is that infant locomotion is destination-directed -infants crawl or walk to reach interesting destinations, to engage in social interactions, or to interact with objects. In short, locomotion is primarily directed toward people, places, and things. In Gibson's (1978) words:

Exploratory skills in a human infant begin with looking around the world; everything within the baby's field of view provides an incentive. When mobility is achieved, the baby first reaches for, then creeps toward and finally walks (or runs) for the attractive goal he or she spies. (p. 610)

Gibson's quote refers to both developmental time and real time. She, like many others, assumed that the allure of distant destinations serves as the motivation for infant's first ever crawling or walking steps and the reason infants get up and go after they become independently mobile (Campos et al., 2000; Piaget, 1954).

Most lab-based studies of infant locomotion and exploration capitalize on the reasonable assumption of destination-directed locomotion. Researchers typically use caregivers, toys, or snacks as incentives to encourage infants to demonstrate their walking proficiency, navigate obstacles, or explore the environment (Kretch \& Adolph, 2017; Lee, Cole, Golenia, \& Adolph, 2017; Rheingold \& Eckerman, 1969). Over dozens of trials, when experimenters entice infants to locomote, infants generally go to the goal. Caregivers also provide motivation for locomotor exploration. They can incite locomotion by calling to infants or by pointing out enticing objects or features of the layout (Franchak, Kretch, Soska, \& Adolph, 2011). During free play, infants also transport objects to caregivers to engage in social interactions (Karasik, Tamis-LeMonda, \& Adolph, 2011).

More typically, infants discover their own destinations. Despite researchers' or caregivers' best-laid plans, infants sometimes go to destinations of their own choosing. In gait studies, infants veer out of the recording area to play with something else in the room (Lee et al., 2017). While encouraged to navigate obstacles, infants go to a shiny screw on the apparatus or stop to pluck lint off the carpet (Adolph, 1997; Gibson et al., 1987). Human infants also create destinations when none are readily available. With everything carefully stowed out of reach, infants still find targets for play—a springy doorstop, a light switch, or a bedspread tassel.

Even in sparse environments such as those used to study isolated infant monkeys, infants still find something to explore. In one illustrative example of a self-constructed destination, an infant monkey playing alone in an empty chamber spied a small protuberance near the ceiling; he spent hours figuring out how to chimney up the wall to reach the tiny bump, and eagerly repeated the feat on subsequent test days (Mears, 1978; see Figure 1A).

Accordingly, the destination-directed hypothesis assumes that infants locomote to interact with people, places, and things—both in standard lab paradigms where experimenters provide incentives to move and under less controlled conditions where infants decide for themselves when to move and where to go. 


\section{Peragration-Driven Locomotion}

An alternative, less intuitive hypothesis is that infants' spontaneous locomotion is not primarily motivated by destinations. Although infants can locomote to reach caregivers and objects, each bout of locomotion need not be motivated by learning about, acquiring, or interacting with a distant person, place, or thing. Infants often engage in locomotor exploration with no proximal goal other than motion of the body through space-what Mears and Harlow $(1975 ; 1978)$ termed "peragration." Infant monkeys run, turn flips, and tumble with no toys, apparatus, or playmates to incite locomotion. Similarly, foals gambol, puppies chase their tails, and human infants run laps around the living room. The promise of unexplored space is sufficiently alluring to instigate locomotion. Infants readily leave their stationary mothers to visit an adjoining room entirely devoid of toys and furniture (Mahler, Pine, \& Bergman, 1975; Rheingold \& Eckerman, 1970). Thus, we refer to the alternative hypothesis - that most of infants' locomotor exploration is not driven by distant destinations -as the peragration hypothesis.

Consistent with the peragration hypothesis, quantification of infants' self-guided locomotor exploration-where infants go, how many steps they take, how far they travel, and what they see as they move-suggests that much of infants' locomotion is not motivated by the allure of an immediate destination (Cole, Robinson, \& Adolph, 2016; Franchak et al., 2011; Karasik, Adolph, Tamis-LeMonda, \& Zuckerman, 2012). Infants mostly take steps in place, or end bouts in the middle of the floor beyond arms' reach of any discernable destination (Cole et al., 2016; Karasik et al., 2012). Even when infants stop near recognizable destinations, they often discover them incidentally over the course of their travels. Data from head-mounted eye tracking show that walking infants rarely fixate a destination before they initiate a bout of locomotion to that location-only about $16 \%$ of bouts (Hoch, Rachwani, \& Adolph, 2017). Moreover, although infants frequently carry objects during locomotor play, they rarely transport them to a particular destination or stop to play with an object in hand (Karasik et al., 2011). Instead, it is the act of carrying that is rewarding (Gibson, 1988; Gibson \& Schmuckler, 1989). Although infants' locomotor exploration can be directed toward destinations, the peragration hypothesis suggests that motion of the self can be "a reinforcer in and of its own right" (Mears \& Harlow, 1975, p. 1879).

\section{Current Study}

Our primary aim was to assess the evidence for the destination-directed and peragration hypotheses. If - as proposed by the destination hypothesis—having destinations to move to or objects to move with serve a crucial role in encouraging locomotion, then we would expect more infant activity in a room filled with interesting toys designed to encourage locomotion than in an empty room. Furthermore, we would expect infants to direct their bouts toward toys and to move with toys when they are available. Conversely, to the extent that the peragration hypothesis is true, we would expect that infants will locomote just as much in a toy-filled room as in room with no toys. High rates of locomotion in the absence of enticing destinations (such as toys) or the encouragement of a caregiver would suggest that destinations are not required to incite locomotion. Moreover, low rates of destination- 
directed locomotion, regardless of the availability of toys, would lend weight to the peragration hypothesis-that locomotion is motivating in and of itself.

To test the destination-directed and peragration hypotheses, we observed 15-month-old infants (an age at which most infants can walk three meters without support) during 20 minutes of free play. Half played in an empty room devoid of toys and furniture, and half played in the same room but with access to several "locomotor" toys. Although any attractive toy can provide an impetus for locomotion, some toys are designed to encourage stationary play (e.g., books, shape-sorters, xylophones), whereas others are designed to be used while in motion (e.g., balls, rolling toys, strollers).

To preclude caregivers from affecting infants' play, in both conditions, we sat caregivers at the edge of the room with a questionnaire and instructed them to refrain from interacting with their infants. An occupied caregiver mimics situations in everyday life when caregivers are busy for relatively short periods of time (doing chores, working on a computer, talking on the phone, etc.) and encourage infants to play by themselves.

In both conditions, we assessed the quantity of infants' spontaneous locomotion based on their accumulated: time in motion, number of bouts, steps, and distance traveled. We scored the percent of bouts that had no apparent destination and those that ended at recognizable destinations: toys (in the toy-filled room), caregivers, and features of the playroom (e.g., door hinge, walls, divot in the floor). Given prior work (Adolph et al., 2012; Cole et al., 2016; Franchak et al., 2011; Hoch et al., 2017; Karasik et al., 2012), we expected infants to show more peragration than destination-driven locomotion overall, and more destinationdriven locomotion in the toy-filled room.

Our secondary aim was to describe patterns of infant locomotor exploration-where infants go, what they do, and whether these patterns differed depending on the availability of toys. Specifically, we asked whether having toys to move to and with would encourage infants to travel farther from their caregivers and into new, unexplored areas. To compare differences in patterns of exploration, we tracked infants' paths through the playroom to calculate the area covered and distance from caregivers. These measures of locomotor exploration reflect opportunities for learning. In everyday life, where infants go and what they see determines what they learn. Thus, differences in the amount of area explored and distance from caregivers can provide insight into the benefits of locomotor exploration.

\section{Method}

\section{Participants}

Twenty 15 -month-old ( $M=15.04, S D=.31$ ) walking infants ( 12 girls, 8 boys) were assigned to a "toy" condition, and 20 (12 girls, 8 boys) were assigned to a "no-toy" condition. Three additional infants in the toy condition were excluded because they became fussy and did not complete the session. Families were recruited from maternity wards of local hospitals and received a framed photograph and tote bag as souvenirs of participation. Twenty-five infants were White, 2 Black, 4 Asian, and 9 had multiple race/ethnicities; 4 were Hispanic or Latino. In a structured interview, parents used cell phone video recordings, 
photos, calendars, and baby books to report their infants' walking experience (Adolph, Vereijken, \& Shrout, 2003). Dating from the first day parents saw their infants walk independently $3 \mathrm{~m}$ (across a room) without stopping or falling, walking experience ranged from $0.2-5.5$ months, and did not differ between the toy $(M=3.1)$ and no-toy $(M=3.5)$ conditions, $t(38)=.93, p>.10$.

\section{Procedure, Playroom, and Materials}

We tested infants in a large laboratory playroom $(4 \mathrm{~m} \mathrm{x} 8 \mathrm{~m})$. Caregivers sat at the edge of the room completing a questionnaire (seated person at top of Figure 2). We instructed caregivers to let their infants play freely on their own. In the rare cases when caregivers got up from the chair or held infants, we subtracted this time from the total session length.

In the toy condition, we scattered five toys evenly around the room; the initial location of the toys was consistent across infants. The toys were designed to be used while walking: a babydoll stroller designed to be pushed; a "popper" that pops plastic balls when rolled; a broom to be carried, wielded, or brushed; a large bouncing ball; and a bucket filled with small balls to be carried, thrown, or chased (Figure 2). In the no-toy condition, the room was empty. In both conditions, shelves were covered with curtains and walls were blank. We filmed infants from four camera views synced onto one video frame for ease of coding. A fixed overhead view captured the entire playroom, two fixed side camera views recorded the length and width of the playroom, and an experimenter operated a handheld camera to obtain a close-up view of infants. The experimenter followed from afar and did not interact with infants or their caregivers (person standing at bottom of Figure 2).

We aimed to collect 20 minutes of independent free play data. Session length was equivalent in the toy $(M=19.2 \mathrm{~min}, S D=2.2)$ and no-toy conditions ( $M=19.9 \mathrm{~min}, S D=.37)$, $t(38)$ $=.98, p>.10$. Following the free play session, we collected standard measures of gait. An experimenter placed infants at one end of a pressure sensitive mat $(1.2 \mathrm{~m} \times 4.9 \mathrm{~m}, 120 \mathrm{~Hz}, 4$ sensors $/ \mathrm{in}^{2}$, protokinetics.com) and caregivers encouraged infants to walk toward them using toys and snacks. We collected 6 walking trials per infant. The two fastest trials were analyzed for measures of standard gait (Lee et al., 2017). Correlations between walking experience and speed $(r(38)=.73, p<.001)$, step length $(r(38)=.46, p=.003)$, and step width $(r(38)=-.73, p<.001)$ validated caregiver reports of walking experience.

\section{Data Coding}

Coders scored videos using Datavyu — an open source, free, video-coding software (datavyu.org) that allows frame-accurate identification of durations and user-defined categorical codes. Videos are available in the Databrary digital library (databrary.org). A primary coder scored $100 \%$ of the video data and a second coder independently scored $25 \%$ of each infant's data to verify inter-observer reliability. For categorical variables, coders agreed on $87 \%-99 \%$ of bouts, all Cohen's $\kappa$ coefficients $\geq .85$, ps $<.001$. For continuous measures, the correlation between coders' scores were high; is 2.94 , all $p s<.001$. Disagreements between coders were resolved through discussion. 
Identification of locomotor bouts.-Coders distinguished bouts of independent locomotion (walking upright or crawling on hands and knees) from stationary periods (no locomotion). Bouts began the first video frame an infant's foot or knee lifted off the ground or changed location by sliding across the floor, and bouts ended the first video frame when both feet or knees were on the ground for at least $500 \mathrm{~ms}$ (Cole et al., 2016; Lee et al., 2017; Adolph et al., 2012). Previous work indicates that 500 ms exceeds infants' typical "double support period" (time between steps when both feet/knees are on the ground) for walking (Bril \& Breniere, 1989; Cole et al., 2016; Hallemans, De Clercq, Otten, \& Aerts, 2005) and crawling (Adolph, Vereijken, \& Denny, 1998). If a pause exceeded $500 \mathrm{~ms}$, but the infant did not appear to stop when viewed at full speed, coders did not separate bouts. This coding rule ensured that locomotor bouts were not erroneously split into multiple bouts. We calculated the percent of time in motion based on the accumulated bout durations relative to the total session time. Coders counted the number of steps per bout. Bouts contained at least one step, but could contain dozens of steps. Steps could be in place or in any direction.

Distance and area explored.-We used a novel digitizing method to record step-to-step, moment-to-moment changes in infants' location in the playroom. Using MatLab software, coders hand digitized infants' location by marking the center of infants' left foot for each step on the large overhead view of the composite coding video. We used the xy coordinates of these points to map the paths infants took through the room (adjusting for lens and perspective distortion). Using known distances, we verified that the digitizing method returned $<5 \%$ error per bout. Estimations of distance and area based on the location of both feet was strongly correlated to estimations using only one foot when computed on a subset of 13 infants; is $\geq .90$.

We calculated distance per bout and total distance traveled by stringing together the digitized distance of each stride end-to-end. Infants accumulated distance regardless of whether they retraced a previous locomotor path. We estimated exploration of new area based on visits to new locations in the playroom. We calculated the amount of new area infants explored by amassing the area covered by a $15-\mathrm{cm}$ radius circle centered on the left foot. Movement to a new part of the room that had not been previously covered was counted as an addition to the cumulative area explored over the course of the session. Thus, if infants took steps in place or revisited a location, they did not get credit for traveling to a new area. The maximum area possible was $29 \mathrm{~m}^{2}$ (the total area of the playroom). Coders also marked the location of the caregivers' chair to calculate the distance between infants and caregivers.

Destinations and toys.-After identifying bouts of locomotion, coders identified where bouts ended using a coding scheme similar to that of Cole et al. (2016) and Hoch et al. (2017). Some bouts ended at a clear destination and some did not. Potential destinations included previously out of reach toys, the seated caregiver, or features of the room (e.g., banging on walls or door; poking finger into a tiny depression in floor; pulling at a wall covering). Bouts ending at no destination could consist of steps in place or bouts that ended when infants stopped locomoting in the middle of the floor, out of arms' reach of a recognizable destination. Occasionally bouts ended before reaching a destination because 
infants fell (lost balance and dropped to the floor). In the toy condition, coders also identified bouts where infants locomoted with a toy in hand.

\section{Results}

Overall, coders identified a total of 5924 locomotor bouts. Across conditions, on average, infants spent $49 \%$ of the session in motion $(S D=10)$, amassed 455 bouts per hour $(S D=$ 98 ), and took 4235 steps per hour $(S D=1144)$. As expected, infants who spent more time in motion took more steps, traveled farther distances, and visited more locations in the room, is $\geq .45, p s \leq .003$. However, in our sample, measures of walking experience and walking skill (speed, step length, step width) did not predict the quantity of locomotion in either condition, $t \mathrm{~s} \leq .29, p \mathrm{~s} \geq .07$.

Infants mostly walked; crawling was rare. Seven infants never crawled, and the most prolific crawler only crawled for $24 \%$ of her steps. Crawling bouts were generally short $(M=4$ steps, $S D=3$, range $=1-33)$ and covered small distances $(M=.44$ meters, $S D=.44$, range $=.01-4.87$ ). Infants in the toy room had a lower percent of crawling bouts (toy: $M=3 \%, S D$ $=3$, no-toy: $M=9 \%, S D=10, t(38)=2.63, p=.01$ ) and crawling steps (toy: $M=1 \%, S D=$ 2, no-toy: $M=4 \%, S D=6, t(38)=2.04, p=.05)$ than infants in the no-toy room. Because crawling was uncommon, we collapsed across crawling and walking, and calculated all outcome measures as rates or proportions to account for differences in recording times. We found no differences in locomotor or exploration measures between boys and girls (all $p \mathrm{~s} \geq$. 11), so gender was combined in subsequent analyses.

\section{Most Bouts Did Not End at Destinations}

Across conditions, most of infants' bouts had no apparent destination. The number of bouts that consisted of steps in place or that ended when infants stopped walking in the middle of the floor did not differ between the toy $(M=65 \%$ of bouts, $S D=10)$ and no-toy conditions $(M=70 \%, S D=10) ; t(38)=1.72, p=.09$. Reciprocally, destinations were also visited in equal proportion.

When infants in the toy room did direct their locomotion to a new destination, they were most likely to visit toys $M=25 \%$ of bouts $(S D=9), F(2,38)=78.82, p<.001$. Less often, infants discovered features of the room such as door handles, bolts in the floor, and gaps to poke fingers $(M=6 \%, S D=4)$, or walked to be near their caregivers $(M=4 \%, S D=3)$. Infants in the no-toy condition traveled to features of the room $(M=19 \%, S D=10)$, and less often, visited their caregivers $(M=11 \%, S D=5 ; t(19)=2.90, p=.009)$.

\section{Infants Used Toys When Toys Were Available}

When toys were available, infants used them. On average, infants in the toy condition produced $80 \%(S D=18)$ of all bouts with at least one toy in hand. While locomoting with a toy, infants were less likely to stop near a new toy $(M=22 \%$ of toy bouts, $S D=9)$ than when infants walked without a toy in hand $(M=46 \%$ of no-toy bouts, $S D=21 ; t(19) p<$. 001). 


\section{No Difference in Overall Quantity of Locomotion}

The quantity of locomotion did not differ between the two room conditions, all $t \mathrm{~s} \leq 92$, all $p \mathrm{~s}$ $\geq .37$ (Figure $3 \mathrm{~A}-\mathrm{F}$ ). Infants spent equal proportions of the session in motion (toy: $M=$ $49 \%, S D=.11$; no-toy: $M=50 \%, S D=.09$ ); took equivalent steps per hour (toy: $M=4379$, $S D=1154$; no-toy: $M=4092, S D=1145$ ); traveled the same overall distance per hour (toy: $M=620 \mathrm{~m}, S D=191$; no-toy: $M=601 \mathrm{~m}, S D=258$ ); initiated locomotion at the same rate (toy: $M=462$ bouts per hour, $S D=107$; no-toy: $M=448$ bouts per hour, $S D=88$ ); took the same number of steps per bout (toy; $M=10, S D=3$; no-toy $M=10, S D=3$; and traveled the same distance per bout (toy: $M=1.41 \mathrm{~m}, S D=.61$; no-toy: $M=1.43 \mathrm{~m}, S D=.70$ ).

\section{Differences in the Quality of Locomotor Bouts}

Bout lengths were highly variable. Every infant produced one bout of at least 34 steps, and bouts ranged from 1-122 steps in the toy room and from 1-136 steps in the no-toy room. Although the average number of steps per bout did not differ between conditions, the distributions of bout lengths differed. Across conditions, many of infants' bouts were short, consisting of only 1-3 steps, and infants took fewer short bouts in the toy condition $(M=$ $40 \%, S D=6)$ than in the no-toy condition $(M=47 \%, S D=13), t(38)=2.22, p=.03$. Infants in the toy condition took more mid-length bouts (4-9 steps) than infants in the no-toy condition (toy: $M=27 \%, S D=5$, no-toy: $M=22 \%, S D=4), t(38)=3.34, p=.002$. The proportion of long bouts (10+ steps) did not differ between conditions (toy: $M=31 \%, S D=$ 12 , no-toy $M=33 \%, S D=9), t(38)=.59, p=.56$. The number of falls per hour did not differ by condition (toy: $M=7.4, S D=8.8$, no-toy $M=8.0, S D=9.8$ ), $t(38)=.178, p=$. 860 .

\section{Different Patterns of Locomotor Exploration}

Area explored.-Although infants in both the toy and no-toy rooms walked similar amounts, the availability of toys affected where infants traveled. Figure 4 shows each infant's locomotor paths over the course of the play session, ordered by the quantity of area explored. Infants visited more regions of the room in the toy condition $(M=62 \%, S D=11)$ than in the no-toy condition $(M=49 \%, S D=22 ; t(38)=2.46, p=.02$; Figure $5 \mathrm{~A})$. The 20minute heat maps in Figure 6 show the average amount of time that infants spent in each part of the room.

Distance from caregivers.-Infants were further from their caregivers in the toy room $(M=3.24 \mathrm{~m}, S D=.75)$ than in the no-toy room $(M=1.76 \mathrm{~m}, S D=1.03) ; t(38)=5.16, p<$. 001. As shown in Figure 5B, infants in the toy room spent less time throughout the session within arms' reach $(100 \mathrm{~cm})$ of their caregivers $(M=17 \%, S D=15)$ compared to infants in the no-toy room $(M=51 \%, S D=27) ; t(38)=4.82, p<.001$.

Real-time analyses.-To examine real-time patterns of exploration, we predicted the amount of cumulative area explored over time using a GEE (Generalized Estimating Equation) centered at 5 minutes of play. As shown in Figure 6, in the first 5 minutes of the session, infants in the toy condition covered $M=7.28 \mathrm{~m}^{2}\left(S E=.45\right.$, Wald $\chi^{2}(1)=262.23, p$ $<.001)$ and did not significantly differ from infants in the no-toy condition, $M=7.21 \mathrm{~m}^{2}(\beta$ $=-.07 \mathrm{~m}^{2}, S E=.91$; Wald $\left.\chi^{2}(1)=.006, p=.938\right)$. However as the session continued, 
infants covered new area at different rates. With each successive bout, infants in the toy condition continued to explore and visit new room locations. Infants in the toy condition added an additional $.85 \mathrm{~m}^{2}$ per minute $\left(\beta=.85, S E=.04\right.$, Wald $\left.\chi^{2}(1)=427.58, p<.001\right)$. Figure 6 shows that the amount of area covered by infants in the toy room steadily increased over time. Infants in the no-toy condition accrued new area at a significantly slower rate, only adding an additional $.54 \mathrm{~m}^{2}$ per minute $\left(\beta=-.31, S E=.12\right.$; Wald $\chi^{2}(1)=6.86, p=$. 009. After the first five minutes, infants in the no-toy room visited fewer new locations than infants in the toy room.

Using the same method, we predicted infants' distance from their caregiver over the course of the session. Five minutes into the session, infants in the toy condition traveled $M=3.51$ meters from their caregivers $\left(S E=.19\right.$; Wald $\left.\chi^{2}(1)=343.20, p<.001\right)$ whereas infants in the no-toy condition remained relatively close by, $M=1.58$ meters ( $\beta=-1.93$ meters, $S E$ $=.28$; Wald $\left.\chi^{2}(1)=47.31, p<.001\right)$. However, over the course of the session, infants in the toy condition moved $.05 \mathrm{~m}$ closer to their caregivers per minute $(\beta=-.05, S E=.02$; Wald $\chi^{2}(1)=13.22, p=.001$ ) whereas infants in the no-toy room (who were already close by) did not change their distance from their caregiver over time $\left(\beta=.05, S E=.02\right.$; Wald $\chi^{2}(1)$ $=7.11, p=.008)$.

Finally, we examined the change in the number of steps per bout over time. After five minutes, infants in the toy condition averaged 8.77 steps per bout $\left(S E=.56\right.$; Wald $\chi^{2}(1)=$ 297.56, $p<.001)$ and did not differ from infants in the no-toy condition, $M=9.84$ ( $\beta=1.07$, $S E=1.08$; Wald $\left.\chi^{2}(1)=.99, p=.321\right)$. However, with each passing minute, infants in the toy condition took .14 more steps per bout $\left(\beta=.14, S E=.05\right.$; Wald $\left.\chi^{2}(1)=8.09, p=.004\right)$ whereas infants in the no-toy condition took .13 fewer steps per bout $(\beta=-.27, S E=.08$; Wald $\left.\chi^{2}(1)=11.50, p=.001\right)$.

\section{Follow-Ups}

To test the hypothesis that simply traveling to the toys' initial locations may account for the increase in the amount of area explored, we tested 6 additional infants in a room with toys placed in a pile three meters from the caregiver, rather than distributed throughout the room. Infants in the toy-pile follow-up condition did not differ from those in the original toy condition in terms of percent time in motion, steps per hour, area explored, or percent time within arms' reach of a caregiver, $t s \leq 1.22, p s \geq .236$ (see red filled circles Figure $3 \mathrm{~A}-\mathrm{F}$, Figure $5 \mathrm{~A}, \mathrm{~B}$ ). These findings suggest that locomoting with toys, not walking to their initial locations, led to an increase in area explored.

We also examined the possibility that infants in the no-toy room spent a greater proportion of the session in one location, not because it was the location of their caregiver, but due to some other feature of the room. We tested 6 additional infants in the no-toy room with the caregiver moved to a new location. Infants in the mom-moved follow-up condition did not differ from those in the original no-toy condition in terms of percent time in motion, steps per hour, area explored, or percent time within arms' reach of a caregiver, $t \mathrm{~s} \leq 1.24, p \mathrm{~s} \geq$. 227 (see blue filled circles Figure 3 A-F, Figure 5 A,B). These findings suggest that in the absence of toys to move to or with, infants were more likely to locomote near their caregiver. 


\section{Discussion}

Our findings support the peragration hypothesis-movement, in and of itself, is enough motivation for infants to get up and go. Infants walked just as much in an empty room as in a room filled with toys. Moreover, most of infants' bouts were not directed toward destinations-only about one third. When infants did stop walking near a destination, they did so at the same rate in both room conditions. Our findings support a growing body of research suggesting that infants do not primarily engage in locomotion to reach destinations such as people, places, or things (Cole et al., 2016; Hoch et al., 2017; Karasik et al., 2012).

Using a novel digitizing method, we recorded step-to-step changes in infants' locomotor exploration. We found that, when toys were available, infants incorporated them into their locomotor bouts, explored more of the playroom and traveled farther from their caregivers. Walking with toys influenced infants' exploratory patterns, but not how much they walked.

\section{Why Locomote: Evidence for Peragration}

Regardless of whether they played in a room filled with toys or in a room with mere space to move, infants spent about half of the session in motion, accumulated an immense number of steps, and traveled large distances. Furthermore, in both room conditions, most of infants' bouts did not lead to any particular destination. Rather, bouts primarily ended in the middle of the floor, out of arms' reach of any discernable destination, or took place near a destination that was already within reach before moving. These findings are consistent with similar studies describing infant play in a lab playroom and at home (Cole et al., 2016; Hoch et al., 2017; Karasik et al., 2011).

In typical lab-based, free-play paradigms, infants play with a caregiver (Adolph et al., 2012; Cole et al., 2016; Hoch et al., 2017; Thurman \& Corbetta, 2017). However, in real-world settings, caregivers are often unavailable for play (Karasik et al., 2014; Tamis-LeMonda et al., 2017). In the current study, with the caregiver occupied, infants in both conditions walked nearly twice as much (about 4200 steps/hour) compared to infants in previous studies where caregivers were free to play (about 2400 steps/hour; Adolph et al., 2012). Interactions with caregivers may decrease the quantity of locomotor play because caregivers encourage more stationary activities. Videos from prior work suggest that caregivers most often initiate stationary play with toys or books, and less frequently encourage locomotor play indoors. As Mears and Harlow noted, "human self-motion play takes place primarily outdoors. When it takes place indoors, parents protest" (1975, p. 1879). Without a caregiver to play with, locomotor play was likely the most interesting activity available to infants.

Infants also displayed a wide range of interesting self-motion behaviors-weaving and twirling, jumping and skipping, and rolling on the floor. In particular, in the no-toy condition, infants were more likely to produce varied forms of locomotion and were three times more likely to crawl than infants in the toy-filled room. Similarly, Mears's (1978) found that even in an empty chamber, without an enticing apparatus to play with or available social partners, infant rhesus monkeys spent considerable time running, tumbling, and exploring their environment. Reminiscent of Mears' determined monkey climbing to the protuberance on the wall, one of our human infants in the no-toy condition was also 
determined to scale the walls: He stretched his fingertips to the top edge of a board obscuring an apparatus and hung suspended by his arms with legs climbing spider-like up the wall (see Figure 1B). When no toys were available, infants created their own fun moving their bodies through the space, and exploiting subtle affordances of their environment.

\section{Patterns of Exploration: The Role of Locomotor Toys}

Despite accumulating similar quantities of locomotion in each room condition, infants covered different amounts of area due to different spatial and temporal patterns of exploration. Although infants in the toy-filled room did not frequently walk to new toys, they incorporated toys into most of their locomotor bouts. Infants in the toy-filled room also visited more of the playroom and traveled farther from their caregivers than infants in the no-toy room. Moreover, infants in the toy-filled room continued to cover new ground and take more steps as the session continued. These differences in exploration may be due to the nature of "locomotor" toys, which are designed to be pushed, pulled, rolled, thrown, and carried.

Infants directed their bouts to destinations at the same low rate across conditions, but in the toy room, the locations of those destinations were constantly in flux. As infants moved with a toy in hand, they re-distributed the toys throughout the room. Thus, the locations of potential destinations (and obstacles) changed over time and may account for the increase in area explored. Moreover, the properties of the toys themselves may have encouraged infants to cover new area. An unwieldy stroller forces infants to take wide turns; small balls bounce and roll, drawing infants into a new area of the room; a large ball bounces away as infants try to pick it up. As a result, the different patterns of exploration between conditions may be byproducts of interacting with locomotor toys. Future studies are needed to examine how toys that encourage stationary play (e.g., puzzles, books, toys too heavy to be carried) affect patterns of locomotor exploration.

In contrast, infants in the no-toy condition explored less of the room and stayed closer to caregivers. They did most of their exploration early on, and covered less area and took fewer steps over time. In a sparse environment with seemingly nothing to do, and nobody to play with, infants chose to run around rather than sit or stand. However, infant exploration in the no-toy room was highly variable. For half the infants in our sample, a large empty room was sufficient to elicit locomotor exploration at rates similar to children in the toy-filled roomthey visited large areas of the playroom and spent little time near their caregiver. In fact, overall, infants in the no-toy room visited caregivers less often than other features of the playroom. Although we designed the playroom to be empty and plain, infants in both conditions discovered "unintended features" of the playroom explore. They ran their hands along the walls of the room, inspected door hinges, and wedged their fingers into indents in the floor. Such destinations were more popular for infants in the no-toy room, whereas infants in the toy-filled room were more likely to walk to toys. Because the features of the room were stationary and did not change locations (e.g., door handle), when infants in the no-toy room made repeat visits to these destinations, they did not cover new ground. Thus, the available types of destinations influenced infants' exploratory patterns. 
The other half of the infants in the no-toy room stuck close to their caregivers-perhaps, for them, their caregiver was the most interesting feature of the room. Because infants were randomly assigned to conditions, we can only speculate that the bimodal distribution of exploration in the no-toy condition reflects individual variability in interests, temperament, attachment, or other factors (Figure 5A). Infants above and below the mean did not differ in terms of age, gender, locomotor experience, or walking proficiency. Indeed, the notion that infants use caregivers as a "secure base" from which to explore an unfamiliar environment (Ainsworth \& Bell, 1970; Rheingold \& Eckerman, 1969; 1970) may reflect experimenters' use of a relatively empty room.

\section{Long-Term Functions of Locomotor Exploration}

Measures of locomotor exploration were highly variable within conditions. In our sample, these measures were not predicted by age, gender, locomotor experience, or walking proficiency. Previous work examining a wider age range shows that infants spend more time in motion, take more steps, and travel farther distances with increased walking experience (Adolph et al., 2012). But intuitively, it seems that at some point peragration play should diminish and destination-directed locomotion should increase. But when? To date, the only study examining developmental changes in the relative proportions of peragration and destination-directed locomotion found no differences between 13-month-old novice and 19month old experienced walking infants (Cole et al., 2016). One possibility is that peragration play remains attractive long after walking skill begins to plateau. Even through preschool ages, children continue to run, jump, and tumble when open floor space is available (van Liempd et al., 2018; McLaren et al., 2012). Future work examining a wide range of ages is needed to determine how locomotor exploration changes over development.

Human and monkey infants are not alone in exhibiting peragration. Foals gambol, lion cubs bound and bounce, puppies frolic, and elephant calves romp. Infants of all species spend an exorbitant amount of time locomoting in the absence of a specific goal (Adolph \& Robinson, 2015). Although researchers cannot definitively state the real-time motivation for bouts of locomotion, many have speculated about the potential long-term benefits of peragration and the role of gross motor play in infant development. It seems that a behavior so abundant, effortful, and costly must serve an essential developmental function. Indeed, non-human infants spend about $20 \%$ of their time and expend around $10 \%$ of their energy on gross motor play (Fagen, 1981). Some researchers propose that gross motor play serves to decrease infants' excess energy (Pellegrini, Dupuis, \& Smith, 2007). Others suggest that gross motor play is essential for social development; young animals denied opportunities for locomotor play show long-term social deficits (Eibl-Eibesfeldt, 1970; Goldfoot, Wallen, Neff, McBrair, \& Goy, 1984). And certainly, through locomotor play, infants learn about their bodies, the environment, and the fit between their bodies and the environment that make a particular action possible - what Gibson termed affordances (Adolph \& Robinson, 2015; Franchak \& Adolph, 2014; Gibson, Adolph, \& Eppler, 1999).

Presumably infants cannot deliberately plan for long-term benefits and do not move with any in mind (how could rat pups or lion cubs know that rough-and-tumble play will facilitate social interactions months or years in the future?). Nonetheless, locomotor exploration 
develops locomotor skills. Learning to walk requires massive amounts of experience. It takes infants roughly 6 months to become proficient walkers, conservatively about 2.6 million steps (assuming 14,000 steps per day) (Adolph et al., 2012). Luckily, typically developing infants seem motivated to move, even in the absence of attractive destinations. Although accumulating a vast number of steps is required, it is not sufficient. Flexible walking skill also requires infants to implement their skill adaptively in novel situations and varied environments (Adolph, 2008; Adolph et al., 2012; Adolph \& Robinson, 2013, 2015). Merely taking steps, like walking on a treadmill, does not teach infants about the body-environment relations necessary to successfully navigate a varied environment in everyday life. Instead, infants likely acquire flexibility in walking skill by experiencing a range of environmental layouts and surfaces. Artificial Intelligence researchers have experimentally tested this hypothesis using simulated humanoid walkers. When trained on varied paths (Ossmy et al., 2018; Urieli, MacAlpine, Kalyanakrishnan, Bentor, \& Stone, 2011) or in varied environments (Heess et al., 2017), simulated walkers perform better in new, untrained settings. Here, we find that toys designed to encourage locomotion prompt infants to cover more ground. Although there were no new layouts or surfaces in our playroom to visit or explore, we suggest that infants' motivation to move ensures that they encounter such opportunities for learning outside the laboratory.

Caregivers can encourage a variety of locomotor experiences by capitalizing on infants' natural tendency for peragration (Mears, 1978). Indeed, the peragration-play model is already employed in the most effective playground designs. Alluring playgrounds and playrooms often feature wide-open spaces where children are free to move (Berg, 2015; Heft, 1988; Luchs \& Fikus, 2013; van Liempd et al., 2018; McLaren et al., 2012). These findings have implications for the design of children's environments such as daycare settings, classrooms, and homes. Furthermore, the amount of spontaneous walking exhibited by typically developing children may provide insights for dosing therapies for children with limited independent mobility. Careful environmental design may provide a natural solution for promoting locomotor exploration in therapeutic and home-based settings.

\section{Conclusion}

Why do infants move? Although infants can and do engage in locomotion directed toward caregivers, toys, and features of the environment, we suggest that reaching these destinations is not the primary motivation for infants' spontaneous locomotion during free play. Rather, the act of locomoting may be self-motivating. Mere space to move is sufficient to elicit large quantities of locomotion. Nevertheless, the availability of toys to move with influences infants' exploratory patterns-where infants go and how far they travel from their caregivers. Moreover, environments that elicit locomotor exploration likely facilitate learning about the varied body-environment relations essential for flexible locomotor skill.

\section{Acknowledgments}

This research was supported by National Institute of Health and Human Development Grant R37-HD033486 to KEA, and by three grants from the NYU Dean's Undergraduate Research Fund, a grant from the NYU Wasserman Center, the 2016 Coons \& Leibowitz Award, and the 2017 Hillary Ann Citrin Award for outstanding departmental honors thesis to SMO. We thank Siffat Islam and Rose Egan for assistance with video coding and members of the NYU Infant Action Lab for comments on earlier drafts of the manuscript. 


\section{References}

Adolph KE (1997). Learning in the development of infant locomotion. Monographs of the Society for Research in Child Development, 62(3, Serial No. 251), 1-140. doi:10.2307/1166199 [PubMed: 9353949]

Adolph KE (2008). Learning to move. Current Directions in Psychological Science, 17, 213-218. [PubMed: 19305638]

Adolph KE, Cole WG, Komati M, Garciaguirre JS, Badaly D, Lingeman JM, ... Sotsky RB (2012). How do you learn to walk? Thousands of steps and dozens of falls per day. Psychological Science, 23, 1387-1394. [PubMed: 23085640]

Adolph KE, \& Robinson SR (2013). The road to walking: What learning to walk tells us about development. In Zelazo P (Ed.), Oxford handbook of developmental psychology (pp. 403-443). New York: Oxford University Press.

Adolph KE, \& Robinson SR (2015). Motor development. In Liben L \& Muller U (Eds.), Handbook of child psychology and developmental science (7th ed., Vol. 2 Cognitive Processes, pp. 114-157). New York: Wiley.

Adolph KE, Vereijken B, \& Denny MA (1998). Learning to crawl. Child Development, 69, 12991312. doi:10.1111/j.1467-8624.1998.tb06213.x [PubMed: 9839417]

Adolph KE, Vereijken B, \& Shrout PE (2003). What changes in infant walking and why. Child Development, 74, 474-497.

Ainsworth MDS, \& Bell SM (1970). Attachment, exploration, and separation: Illustrated by the behavior of one-year-olds in a strange situation. Child development, 49-67. [PubMed: 5490680]

Berg S (2015). Children's activity levels in different playground environments: An observational study in four Canadian preschools. Early Childhood Education Journal, 43, 281-287.

Bril B, \& Breniere Y (1989). Steady-state velocity and temporal structure of gait during the first six months of autonomous walking. Human Movement Science, 8, 99-122.

Campos JJ, Anderson DI, Barbu-Roth MA, Hubbard EM, Hertenstein MJ, \& Witherington DC (2000). Travel broadens the mind. Infancy, 1, 149-219.

Cole WG, Robinson SR, \& Adolph KE (2016). Bouts of steps: The organization of infant exploration. Developmental Psychobiology, 58, 341-354. [PubMed: 26497472]

Eibl-Eibesfeldt I (1970). Ethology: The biology of behavior New York, NY: Holt, Rinehart, \& Winston.

Fagen R (1981). Animal play behavior New York, NY: Oxford University Press.

Franchak JM, \& Adolph KE (2014). Affordances as probabilistic functions: Implications for development, perception, and decisions for action. Ecological Psychology, 26, 109-124. [PubMed: 24954997]

Franchak JM, Kretch KS, Soska KC, \& Adolph KE (2011). Head-mounted eye tracking: A new method to describe infant looking. Child Development, 82, 1738-1750. doi:10.1111/j. 1467-8624.2011.01670.x [PubMed: 22023310]

Gibson EJ (1978). C'est moi. Contemporary Psychology: A Journal of Reviews, 23, 609-614.

Gibson EJ (1988). Exploratory behavior in the development of perceiving, acting, and the acquiring of knowledge. Annual Review of Psychology, 39, 1-41.

Gibson EJ, Adolph KE, \& Eppler MA (1999). Affordance. In Wilson RA \& Keil F (Eds.), MIT encyclopedia of the cognitive sciences (pp. 4-6). Cambridge, MA: MIT Press.

Gibson EJ, Riccio G, Schmuckler MA, Stoffregen TA, Rosenberg D, \& Taormina J (1987). Detection of the traversability of surfaces by crawling and walking infants. Journal of Experimental Psychology: Human Perception and Performance, 13, 533-544. [PubMed: 2965745]

Gibson EJ, \& Schmuckler MA (1989). Going somewhere: An ecological and experimental approach to development of mobility. Ecological Psychology, 1, 3-25.

Goldfoot DA, Wallen K, Neff DA, McBrair MC, \& Goy RW (1984). Social influences on the display of sexually dimorphic behavior in rhesus monkeys: isosexual rearing. Archives of Sexual Behavior, 13, 395-412. [PubMed: 6542772] 
Hallemans A, De Clercq D, Otten B, \& Aerts P (2005). 3D joint dynamics of walking in toddlers: A cross-sectional study spanning the first rapid development phase of walking. Gait and Posture, 22, 107-118. [PubMed: 16139745]

Heess S, D T, Sriram S, Lemmon J, Merel J, Wayne G, ... Silver D (2017). Emergence of locomotion behaviours in rich environments arXiv preprint arXiv:1707.02286.

Heft H (1988). Affordances of children's environments: A functional approach to environmental description. Children's Environment Quarterly, 5, 29-37.

Hoch J, Rachwani J, \& Adolph KE (2017, 4). Why do infants move? Locomotor exploration is more random than destination directed. Paper presented at the meeting of the Society for Research in Child Development, Austin, TX.

Karasik LB, Adolph KE, Tamis-LeMonda CS, \& Zuckerman A (2012). Carry on: Spontaneous object carrying in 13-month-old crawling and walking infants. Developmental Psychology, 48, 389-397. [PubMed: 22081880]

Karasik LB, Tamis-LeMonda CS, \& Adolph KE (2011). Transition from crawling to walking and infants' actions with objects and people. Child Development, 82, 1199-1209. [PubMed: 21545581]

Kretch KS, \& Adolph KE (2017). The organization of exploratory behaviors in infant locomotor planning. Developmental Science

Lee DK, Cole WG, Golenia L, \& Adolph KE (2017). The cost of simplifying complex developmental phenomena: A new perspective on learning to walk. Developmental Science

Luchs A, \& Fikus M (2013). A comparative study of active play on differently designed playgrounds. Journal of Adventure Education and Outdoor Learning, 13, 206-222.

Mahler M, Pine F, \& Bergman A (1975). The psychological birth of the human infant New York: Basic Books.

McLaren C, Ruddick S, Edwards G, Zabjek K, \& McKeever P (2012). Children's Movement in an Integrated Kindergarten Classroom: Design, Methods and Preliminary Findings. Children Youth and Environments, 22(1), 145-177.

Mears CE (1978). Play and development of cosmic confidence. Developmental Psychology, 14, 371378.

Mears CE, \& Harlow HF (1975). Play, early and eternal. Proceedings of the National Academy of Sciences, 72, 1878.

Ossmy O, Hoch J, MacAlpine P, Hasan S, Stone P, \& Adolph K (2018). Variety wins: Soccer-playing robots in infant walking. Frontiers in Neurorobotics, 12.

Pellegrini AD, Dupuis D, \& Smith PK (2007). Play in evolution and development. Developmental Review, 27, 261-276.

Piaget J (1954). The construction of reality in the child New York: Basic Books.

Rheingold HL, \& Eckerman CO (1969). The Infant's Free Entry into a New Environment. Journal of Experimental Child Psychology, 8, 271-283. [PubMed: 5356738]

Rheingold HL, \& Eckerman CO (1970). The infant separates himself from his mother. Science, 168, 78-83. [PubMed: 5417062]

Tamis-LeMonda CS, Kuchirko Y, Luo R, Escobar K, \& Bornstein MH (2017). Power in methods: language to infants in structured and naturalistic contexts. Developmental Science

Thurman SL, \& Corbetta D (2017). Spatial exploration and changes in infant-mother dyads around transitions in infant locomotion. Developmental Psychology, 53(7), 1207-1221. [PubMed: 28459258]

Urieli D, MacAlpine P, Kalyanakrishnan S, Bentor Y, \& Stone P (2011). On optimizing interdependent skills: A case study in simulated 3D humanoid robot soccer Paper presented at the Proceedings of the 10th International Conference on Autonomous Agents and Multiagent Systems, Richland, SC.

van Liempd HIM, Oudgenoeg-Paz O, Fukkink RG, \& Leseman PP (2018). Young children's exploration of the indoor playroom space in center-based childcare. Early Childhood Research Quarterly, 43, 33-41. 


\section{Research Highlights}

- Infants took just as many steps in an empty room as in a toy-filled room, and most of their walking bouts had no apparent destination.

- Although mere space to move is sufficient to elicit locomotor exploration, moving with toys encouraged infants to leave their caregiver and to explore new areas of the room.

- Over the course of the session, infants in the toy-filled room continued to take more steps and explore new ground, whereas infants in the no-toy room did not.

- Left to entertain themselves, infants in both conditions walked more than infants in similar studies who played with their caregivers. 
A

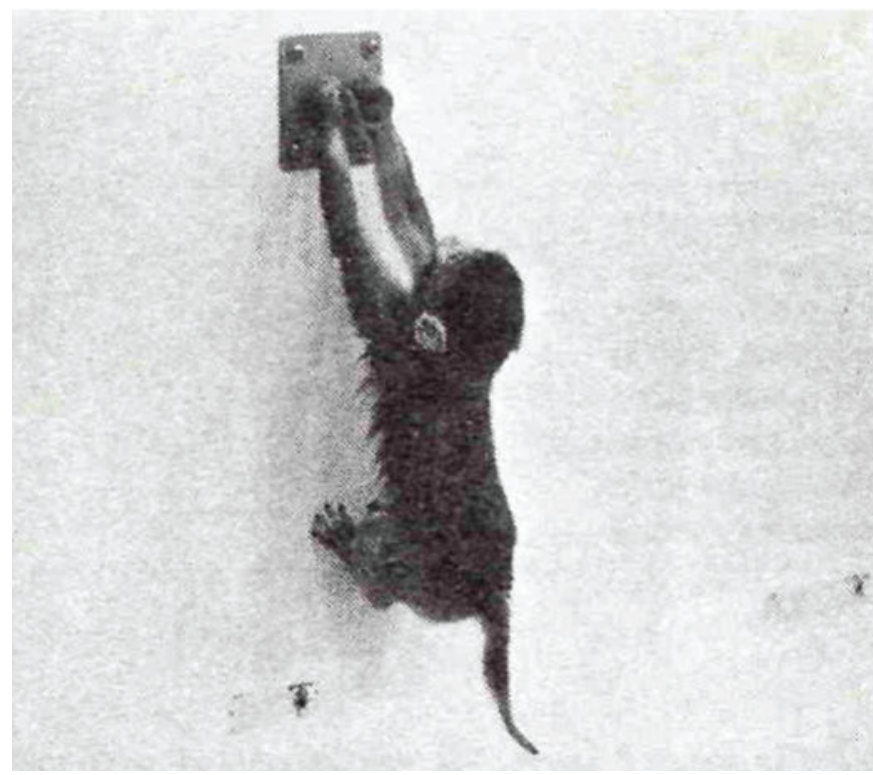

B

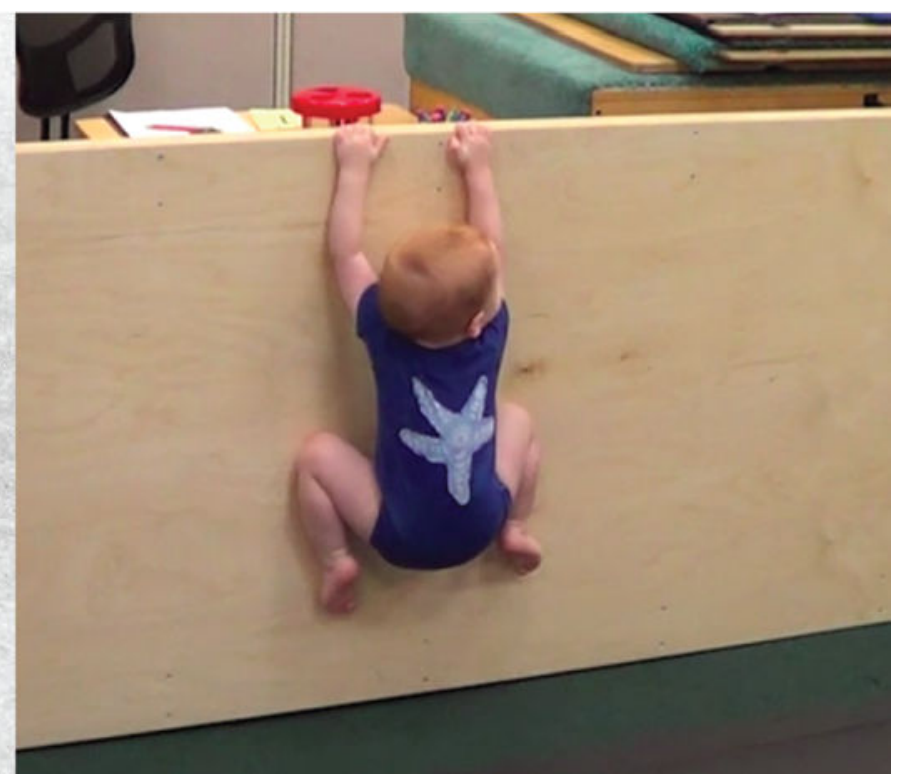

Figure 1.

Locomotor play in an empty room. (A) An infant rhesus monkey climbed up a wall to reach a protuberance in an otherwise empty chamber (Mears, 1978). (B) A human infant in the notoy room stretched his fingertips to the top edge of a board obscuring an apparatus and hung suspended by his arms, with legs climbing spider-like up the wall. 


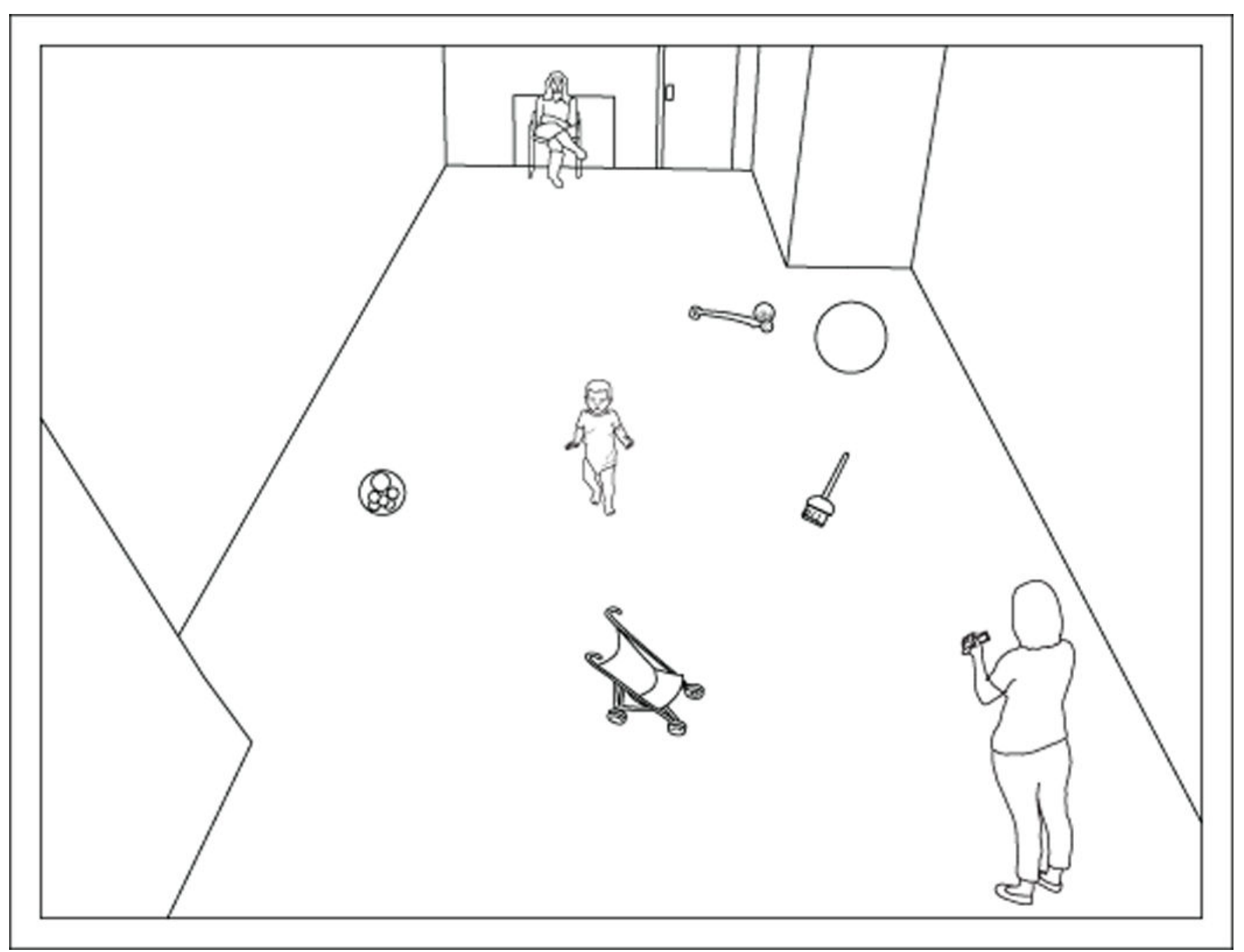

Figure 2.

Playroom in the toy condition. The no-toy playroom was equivalent, but no toys were present. Caregivers sat at the edge of the room completing a questionnaire. An experimenter filmed infants from a distance. Neither adult interacted with infants. 

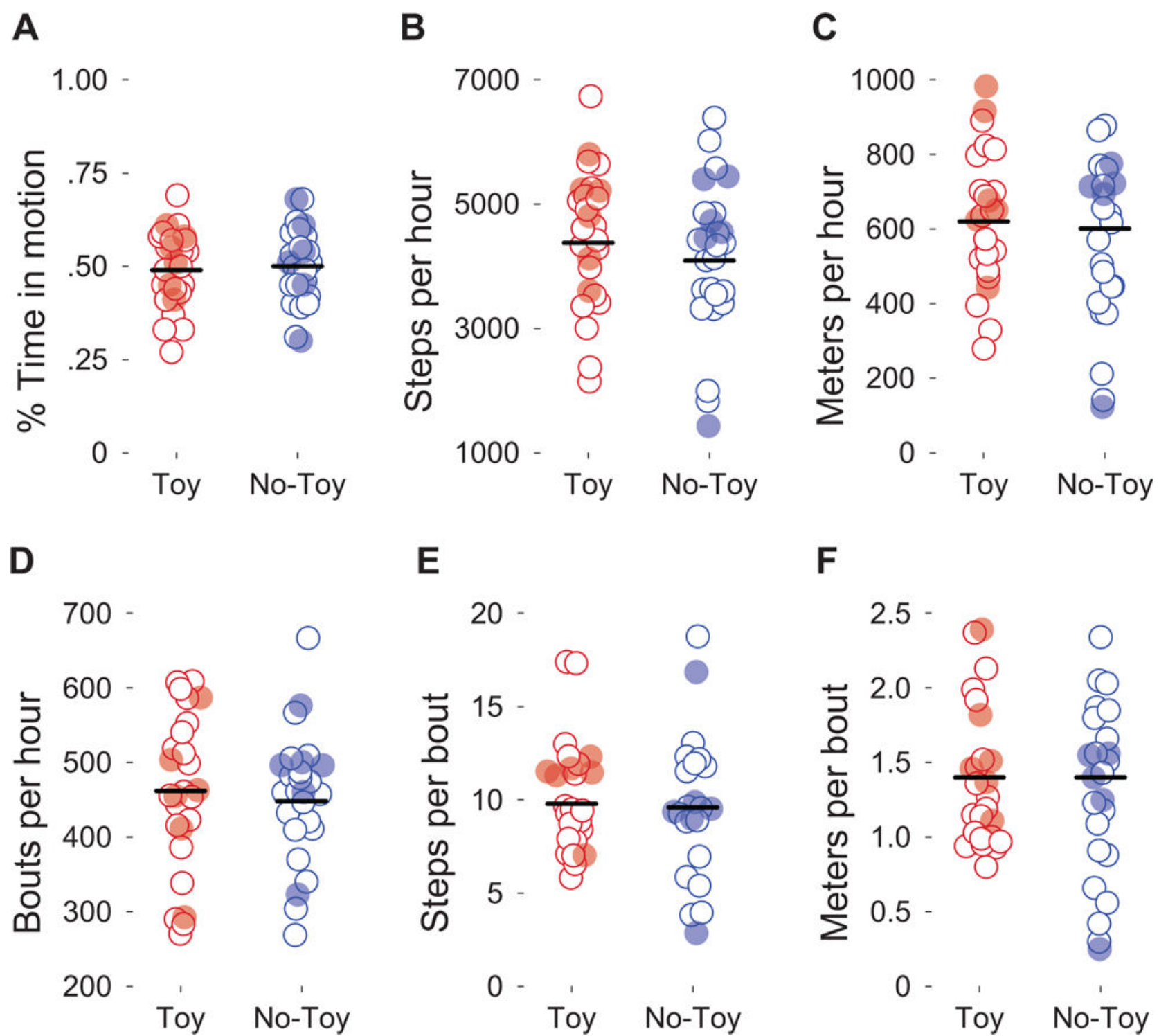

E

$\mathbf{F}$
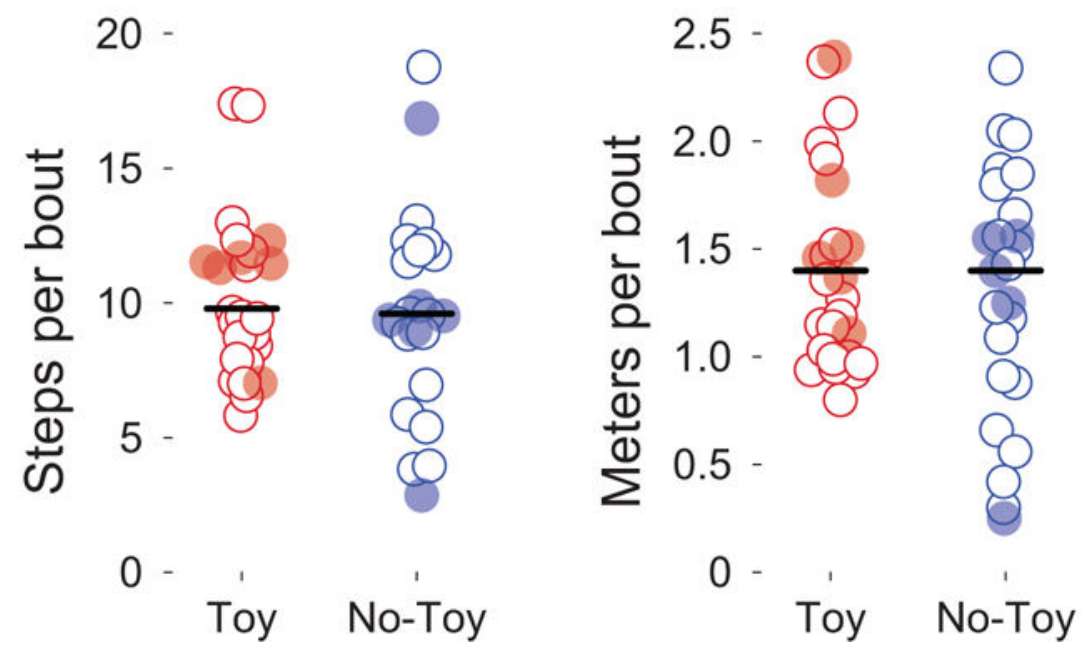

Figure 3.

No differences in quantity of locomotion in the toy-filled room versus the no-toy room in: (A) percent of time in motion, (B) number of steps per hour, (C) meters traveled per hour, (D) bouts per hour, (E) number of steps per bout, and (F) meters traveled per bout. Open circles plot infants in toy and no-toy conditions. Filled circles show infants in the follow up conditions with toys piled in one place (red) and caregiver moved to a different location (blue). Data from these infants are not included in the group means (horizontal black bars). 


\section{A Toy}

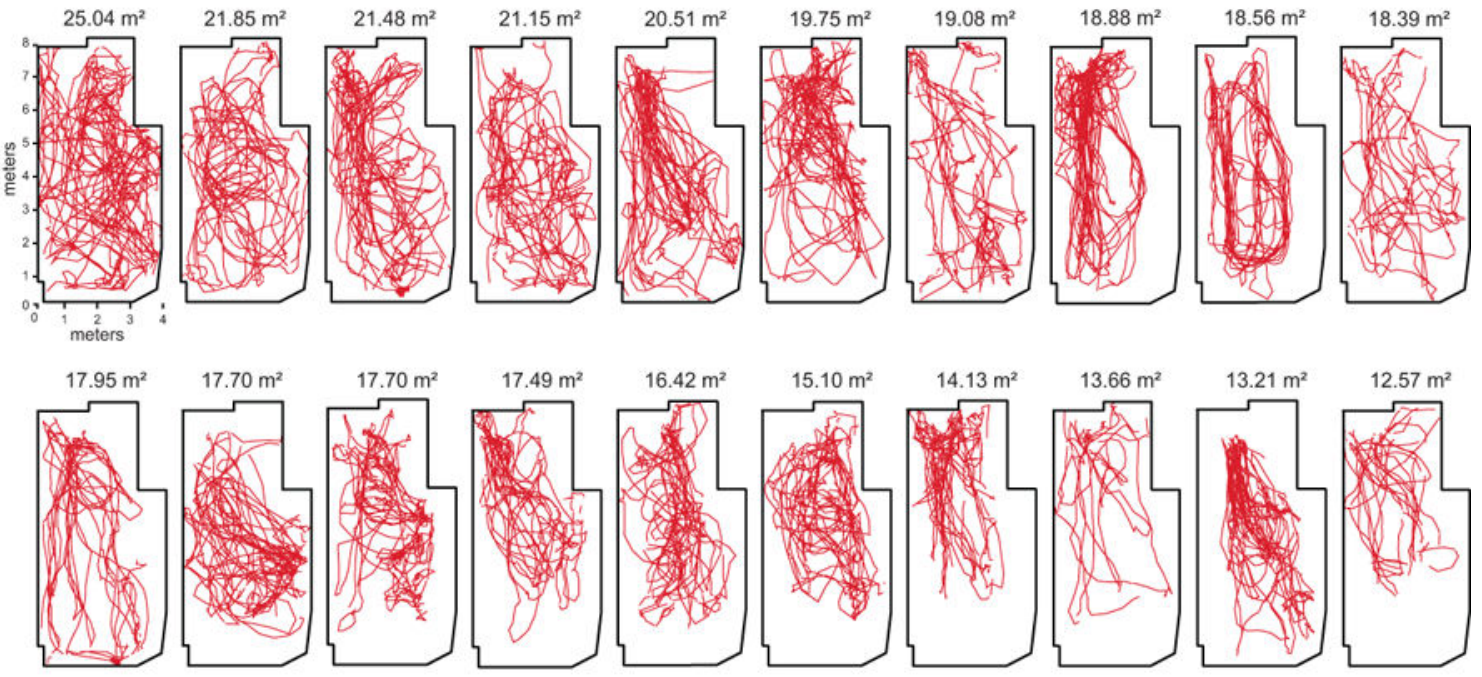

\section{B No-Toy}
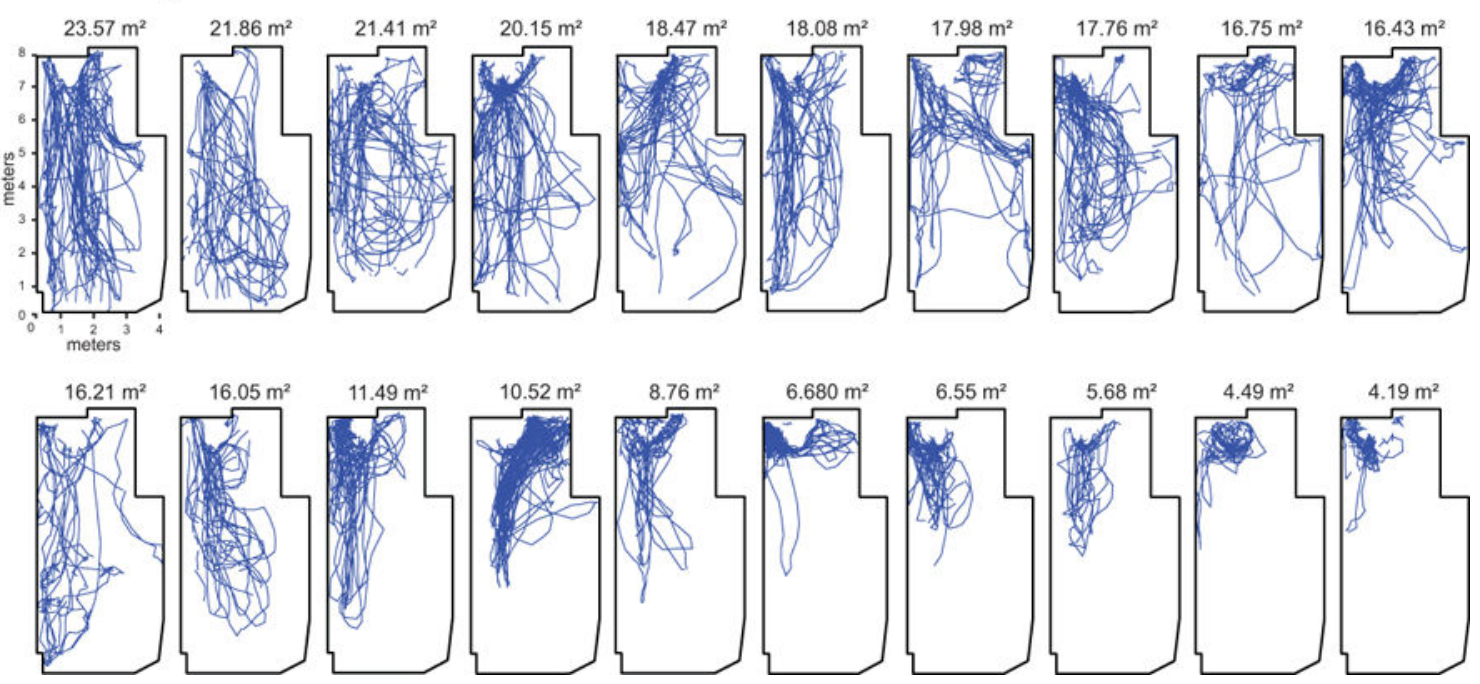

Figure 4.

Locomotor paths for each infant in (A) the toy condition and (B) the no-toy condition derived from the novel digitizing technique. Paths are ordered from most to least area covered (maximum area possible $29 \mathrm{~m}^{2}$ ). 


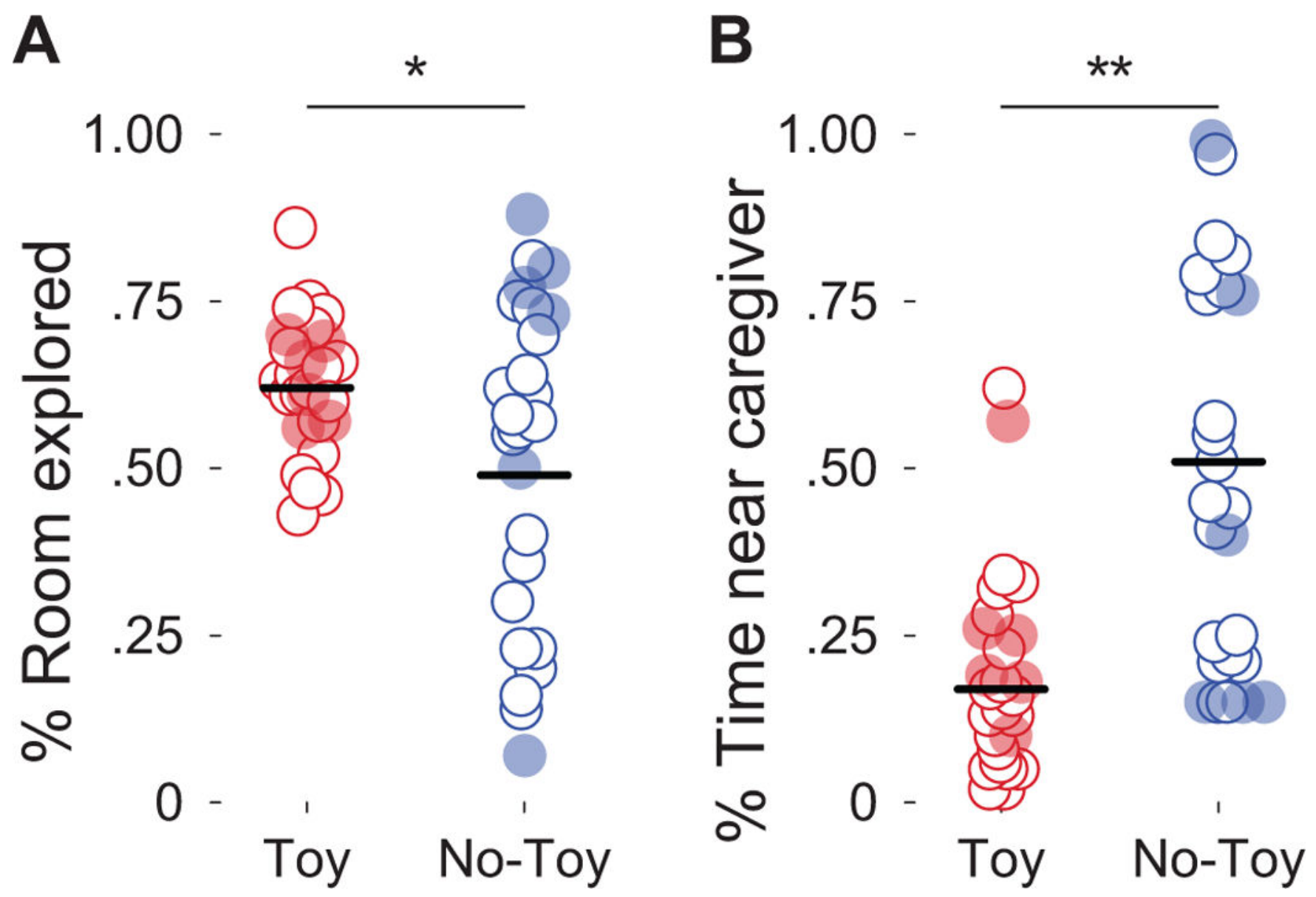

Figure 5.

Infants in the toy condition (A) explored a greater percent of the room and (B) spent a lower percent of the session within $100 \mathrm{~cm}$ of the caregiver. Open circles plot infants in toy and notoy conditions. Filled circles show infants in the follow up conditions (toys-piled in red and mom-moved in blue) and are not included in the group means (horizontal black bars).

Asterisks denote statistical significance. 


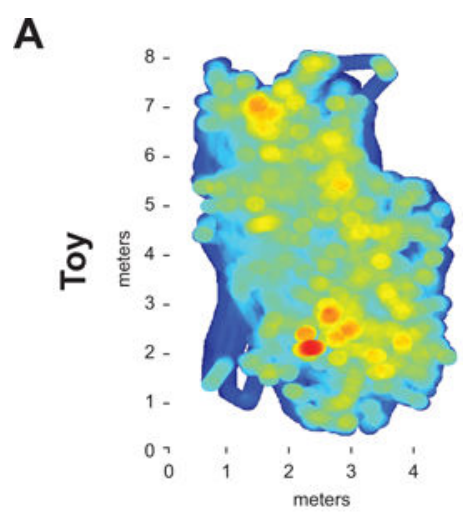

$5 \mathrm{~min}$

B

Figure 6.

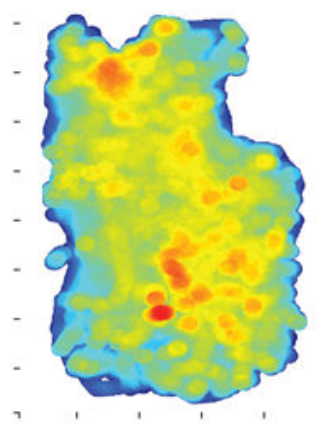

$10 \mathrm{~min}$

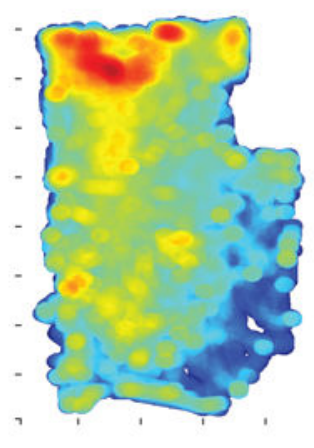

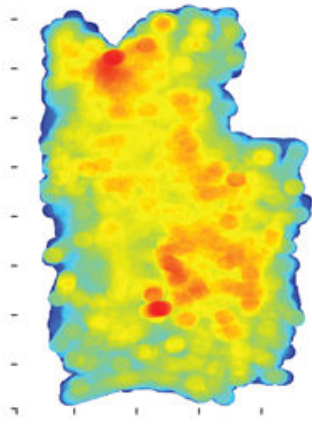

$15 \mathrm{~min}$

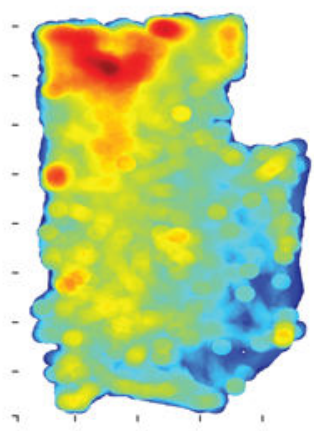

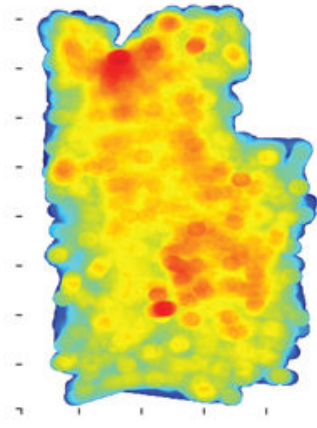

$20 \mathrm{~min}$

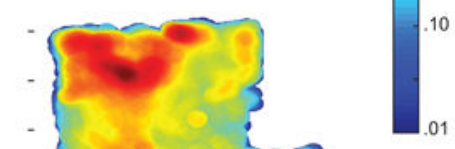

Heat maps showing the average number of seconds spent in each location in the playroom (estimated as a $15-\mathrm{cm}$ radius circle centered on the left foot) at 5, 10, 15 and 20 minutes into the session. Infants in the toy-filled room (A) covered more area and continued to visit new locations over time. (B) Infants in the no-toy room spent more time near their caregivers (the dark red patches at the top of each map) and visited new room locations at a slower rate. Note that time in each location is displayed on a logarithmic scale with the highest value 10000 times the lowest value. 